\title{
Review Article \\ The Cardioprotective Actions of Hydrogen Sulfide in Acute Myocardial Infarction and Heart Failure
}

\author{
David J. Polhemus, ${ }^{1}$ John W. Calvert, ${ }^{2}$ Javed Butler, ${ }^{3}$ and David J. Lefer ${ }^{1}$ \\ ${ }^{1}$ Department of Pharmacology and Experimental Therapeutics and Cardiovascular Center of Excellence, \\ LSU Health Sciences Center, New Orleans, LA 70112, USA \\ ${ }^{2}$ Department of Surgery, Emory University School of Medicine, Atlanta, GA 30322, USA \\ ${ }^{3}$ Department of Medicine, Emory University School of Medicine, Atlanta, GA 30322, USA \\ Correspondence should be addressed to David J. Lefer; dlefel@lsuhsc.edu
}

Received 27 February 2014; Revised 30 April 2014; Accepted 16 May 2014; Published 22 June 2014

Academic Editor: Gisele Zapata-Sudo

Copyright (C) 2014 David J. Polhemus et al. This is an open access article distributed under the Creative Commons Attribution License, which permits unrestricted use, distribution, and reproduction in any medium, provided the original work is properly cited.

It has now become universally accepted that hydrogen sulfide $\left(\mathrm{H}_{2} \mathrm{~S}\right)$, previously considered only as a lethal toxin, has robust cytoprotective actions in multiple organ systems. The diverse signaling profile of $\mathrm{H}_{2} \mathrm{~S}$ impacts multiple pathways to exert cytoprotective actions in a number of pathological states. This paper will review the recently described cardioprotective actions of hydrogen sulfide in both myocardial ischemia/reperfusion injury and congestive heart failure.

\section{Introduction}

Hydrogen sulfide $\left(\mathrm{H}_{2} \mathrm{~S}\right)$ has long been viewed simply as a toxic gas with an odorous smell. Its dangerous properties were recognized as far back as the 18th Century when cesspit workers exposed to high environmental levels of $\mathrm{H}_{2} \mathrm{~S}$ developed eye inflammation and bacterial infection [1] (Figure 1). More recently, however, $\mathrm{H}_{2} \mathrm{~S}$ was discovered to exist endogenously and has emerged as an omnipotent signaling molecule, specifically in the cardiovascular system [2-7]. Several years ago, cardiovascular researchers largely focused on the other gaseous signaling molecules, nitric oxide (NO) and carbon dioxide (CO). Consensus formed that $\mathrm{NO}$ and $\mathrm{CO}$ based therapies protect the brain, heart, and circulation against a number of cardiovascular diseases [814]. Because endogenously produced $\mathrm{H}_{2} \mathrm{~S}$ is a gaseous signaling molecule capable of regulating physiological processes (similar to NO and CO), we investigated its potential role as a cardioprotective agent. Our group has shown specifically that $\mathrm{H}_{2} \mathrm{~S}$ protects against myocardial ischemia/reperfusion $(\mathrm{MI} / \mathrm{R})$ injury and preserves cardiac function following the onset of heart failure in various preclinical model systems.

\section{Endogenous Synthesis of Hydrogen Sulfide in Mammals}

Experimental studies reveal that $\mathrm{H}_{2} \mathrm{~S}$ is produced at nano- to micromolar levels both enzymatically and nonenzymatically [15]. The continuous enzymatic production is critical due to the extremely short biological half-life of the molecule (estimated to be between seconds to minutes) [16, 17]. Nonenzymatic $\mathrm{H}_{2} \mathrm{~S}$ can form via the reduction of thiolcontaining molecules when $\mathrm{H}_{2} \mathrm{~S}$ is released from sulfur stores such as sulfane sulfur. Two $\mathrm{H}_{2} \mathrm{~S}$ producing enzymes are part of the cysteine biosynthesis pathway: cystathionine gamma lyase (CSE) and cystathionine beta synthase (CBS). These enzymes coordinate with L-cysteine to produce $\mathrm{H}_{2} \mathrm{~S}$, L-serine, pyruvate, and ammonia $[2,4]$. Originally, the endogenous production of $\mathrm{H}_{2} \mathrm{~S}$ in the brain was attributed to CBS [18]. However, more recently, the third enzyme, 3mercaptopyruvate sulfurtransferase (3-MST), was reported to manufacture roughly $90 \%$ of $\mathrm{H}_{2} \mathrm{~S}$ in the brain and is largely concentrated in the mitochondria [19]. 3-MST produces $\mathrm{H}_{2} \mathrm{~S}$ from $\alpha$-ketoglutarate and L-cysteine via metabolic actions with cysteine aminotransferase and glutamate [19]. The distribution and function of CBS, CSE, and 3-MST under normal 
Evolution of $\mathrm{H}_{2} \mathrm{~S}$ from toxic gas to physiological mediator

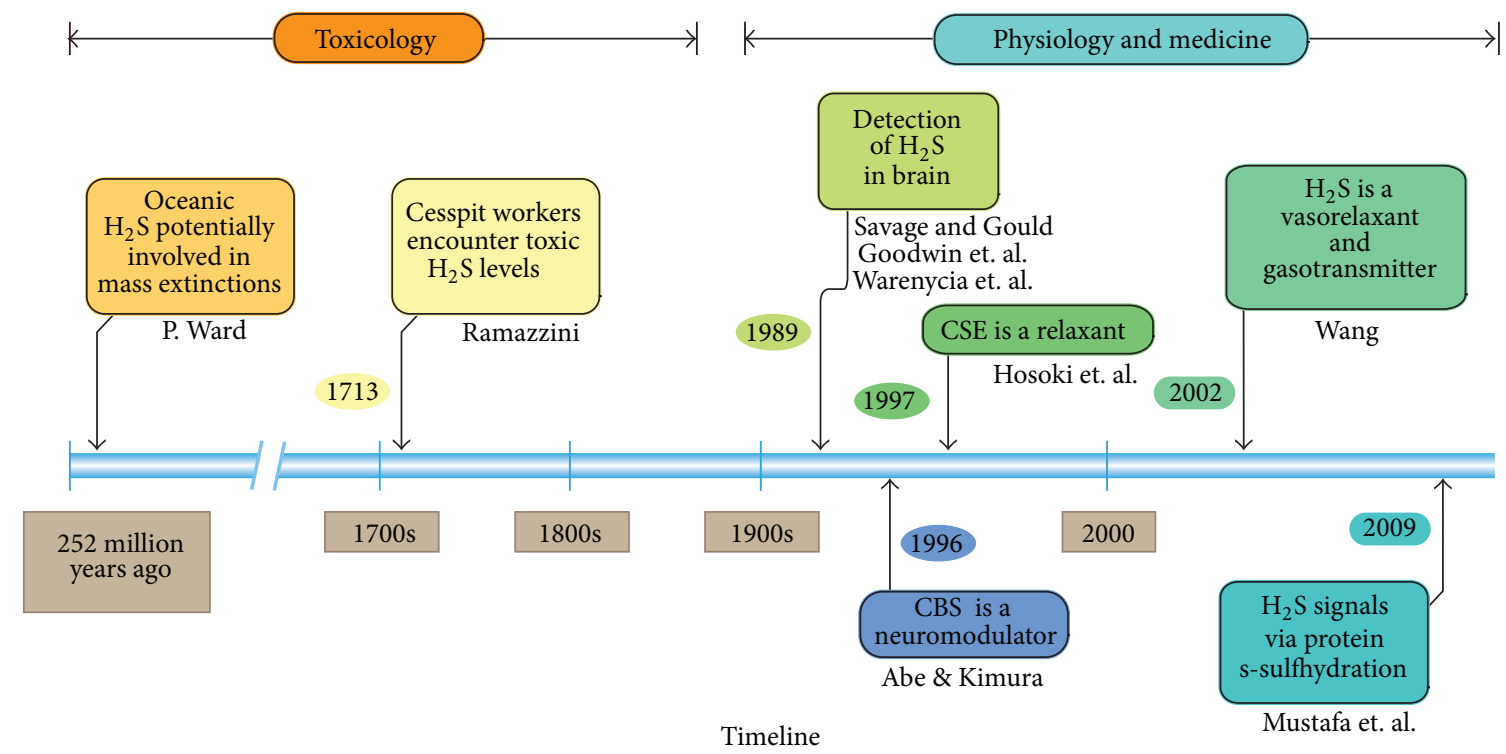

FIGURE 1: History of the emergence of hydrogen sulfide $\left(\mathrm{H}_{2} \mathrm{~S}\right)$ as a physiological regulator of cardiovascular homeostasis. $\mathrm{H}_{2} \mathrm{~S}$ is believed to be responsible for mass extinctions that occurred over 250 million years ago as toxic gases were spewed from deep in the earth. In the 1700 s, $\mathrm{H}_{2} \mathrm{~S}$ was linked to injuries sustained by sewer workers. In 1989, $\mathrm{H}_{2} \mathrm{~S}$ was detected in the brain of mammals by several groups. In 1996$1997, \mathrm{H}_{2} \mathrm{~S}$ was shown to modulate vascular tone and neuronal function. Finally in 2002, $\mathrm{H}_{2} \mathrm{~S}$ was implicated in vascular function and blood pressure regulation in seminal studies. $\mathrm{H}_{2} \mathrm{~S}$ was then shown to posttranslationally modify proteins via s-sulfhydration by Dr. Sol Snyder's group. Adopted from Hideo Kimura, Ph.D. Ward [71], Savage and Gould [72], Goodwin et al. [73], Warenycia et al. [74], and Mustafa et al. [75].

physiological conditions remain controversial and unclear. However, we have found that all 3 enzymes are expressed in the heart [20] and a global genetic deletion of CSE (global CBS and 3MST KO mice have not yet been reported) results in significant reductions in myocardial and circulating $\mathrm{H}_{2} \mathrm{~S}$ and sulfane sulfur levels [21]. As this field advances, more discoveries will likely unfold and give us more insight into the physiological mechanism of these enzymes.

\section{Hydrogen Sulfide and Myocardial Infarction}

Myocardial infarction remains a leading cause of mortality worldwide [22]. It is well established that myocardial ischemia/reperfusion (MI/R) injury stimulates tissue destruction and often leads to heart failure [23]. While reperfusion relieves ischemia, it also results in a complex reaction that leads to cell injury caused by inflammation and oxidative damage [24]. In the first study, to establish an in vivo model for MI/R in mice, the left coronary artery (LCA) was transiently ligated and reperfusion followed by removal of the ligating suture [25]. Following 30 minutes of ischemia, mice were administered sodium sulfide $\left(\mathrm{Na}_{2} \mathrm{~S}\right)(50 \mu \mathrm{g} / \mathrm{kg})$ into the left ventricle $(\mathrm{LV})$ lumen. Mice receiving the donor at the time of reperfusion displayed a $72 \%$ reduction in infarct size compared to the vehicle treated mice [25]. Cardiac troponinI (cTnI) evaluation, an additional marker for myocardial injury, also affirmed myocardial preservation in the $\mathrm{H}_{2} \mathrm{~S}$ treated group. Additionally, LV echocardiographic analysis following 72 hours of reperfusion revealed that $\mathrm{H}_{2} \mathrm{~S}$ treated mice displayed no increase in post-MI/-R LV dimensions (left ventricular end-diastolic dimensions and left ventricular end-systolic dimensions), while the vehicle treated group showed significantly increased wall thickening [25].

A subsequent study examined the impact of genetically modifying an enzyme responsible for much of endogenous $\mathrm{H}_{2} \mathrm{~S}$ production (CSE) [25]. Using a heavy chain $\alpha \mathrm{MHC}$ promoter in coordination with the cystathionine (Cth) gene sequence (responsible for CSE production), a cardiac specific transgene mouse was created to constitutively overexpress the CSE enzyme. These mice had a significantly elevated production rate of $\mathrm{H}_{2} \mathrm{~S}$, as expected, and were subjected to a similar MI/R protocol. Following 45 minutes of ischemia and 72 hours of reperfusion, the transgenic mice expressed significantly reduced infarct size compared to the wild-type group. These findings reveal that both exogenous donors and endogenously elevated $\mathrm{H}_{2} \mathrm{~S}$ serve to protect against ischemiareperfusion injury in the murine heart.

The mechanisms by which $\mathrm{H}_{2} \mathrm{~S}$ protected against MI/R injury, we found, are through preservation of mitochondrial function, reduction of cardiomyocyte apoptosis, antiinflammatory responses, and antioxidant effects that limit cell damage and death. Mitochondria are essential for cell survival and energy production. They are unique in that they regulate cell death and apoptosis and maintain oxidative phosphorylation following MI in a manner that helps to preserve myocyte survival [26]. In vitro experiments revealed a dose-dependent reduction in oxygen consumption followed 
by a recovery to baseline levels in the $\mathrm{H}_{2} \mathrm{~S}$ treated group [25]. Additionally, $\mathrm{H}_{2} \mathrm{~S}$ at the time of reperfusion preserved function as noted by increases in efficiency of complexes I and II of the electron transport chain. In an ischemia setting, mitochondrial function can be compromised as a result of an increase in reactive oxygen species (ROS), which can lead to uncoupling and increased infarction [27, 28]. High doses of $\mathrm{H}_{2} \mathrm{~S}$ can slow down cellular respiration by inhibiting cytochrome c oxidase, lowering metabolism into a protected, preconditioned state [29]. The inhibition of respiration has been shown to protect against MI/R injury by limiting the generation of ROS species [30, 31].

We also found $\mathrm{H}_{2} \mathrm{~S}$ to have antioxidant properties mediated by Nrf-2 signaling. Nrf-2 is a potent antioxidant transcription factor that can translocate from the cytosol to the nucleus to induce various antioxidant proteins. This protein promotes oxidant defenses and reduces oxidative stress. When mice were treated with a long acting $\mathrm{H}_{2} \mathrm{~S}$ donor, diallyl trisulfide (DATS), following acute MI, Nrf-2 translocated from the cytosol to the nucleus while overall levels of Nrf2 remained constant within the cell [32]. Additional studies further demonstrate the downstream signaling of $\mathrm{Nrf} 2$ induced by $\mathrm{H}_{2} \mathrm{~S}$ to promote antioxidant defenses [33-36]. These cardioprotective actions, we believed, would also prove to be protective in other heart diseases. We then investigated $\mathrm{H}_{2} \mathrm{~S}$ in heart failure.

\section{Hydrogen Sulfide and Heart Failure}

Heart failure is the heart's inability to sufficiently supply blood to meet the needs of the body. In the United States, it has become the most common discharge diagnosis in patients 65 years or older and treatments remain insufficient $[37,38]$. Therefore, the investigation of therapeutic options to attenuate cardiac dysfunction in heart failure remains clinically relevant and critical.

Our group found that heart failure patients have marked reductions in circulating $\mathrm{H}_{2} \mathrm{~S}$ levels compared to age matched controls (Figure 2). In a recent study, Peter et al. reported elevated plasma $\mathrm{H}_{2} \mathrm{~S}$ levels in patients with vascular disease [39]. The results in this study do not contradict our findings of reduced $\mathrm{H}_{2} \mathrm{~S}$ in heart failure patients. The patient profiles in the two studies are dissimilar and do not represent similar disease states. The heart failure patients analyzed in the current study suffer from severe end stage cardiomyopathy with reduced heart function [40]. Conversely, patients in the recent study suffered from coronary or peripheral arterial disease. We do not take these findings as conflicting but acknowledge that changes in $\mathrm{H}_{2} \mathrm{~S}$ are dependent on numerous factors, such as the type of cardiovascular disease (i.e., coronary heart disease or heart failure). The discovery of $\mathrm{H}_{2} \mathrm{~S}$ deficiency in heart failure patients led to our exploration of $\mathrm{H}_{2} \mathrm{~S}$ therapy for the treatment of heart failure. In our preliminary study to create a heart failure in the murine heart, transverse aortic constriction (TAC) between the brachiocephalic trunk and the left carotid artery produced a hypertrophic, pressure overload induced model [20]. We observed greater than a $60 \%$ decrease in both myocardial and
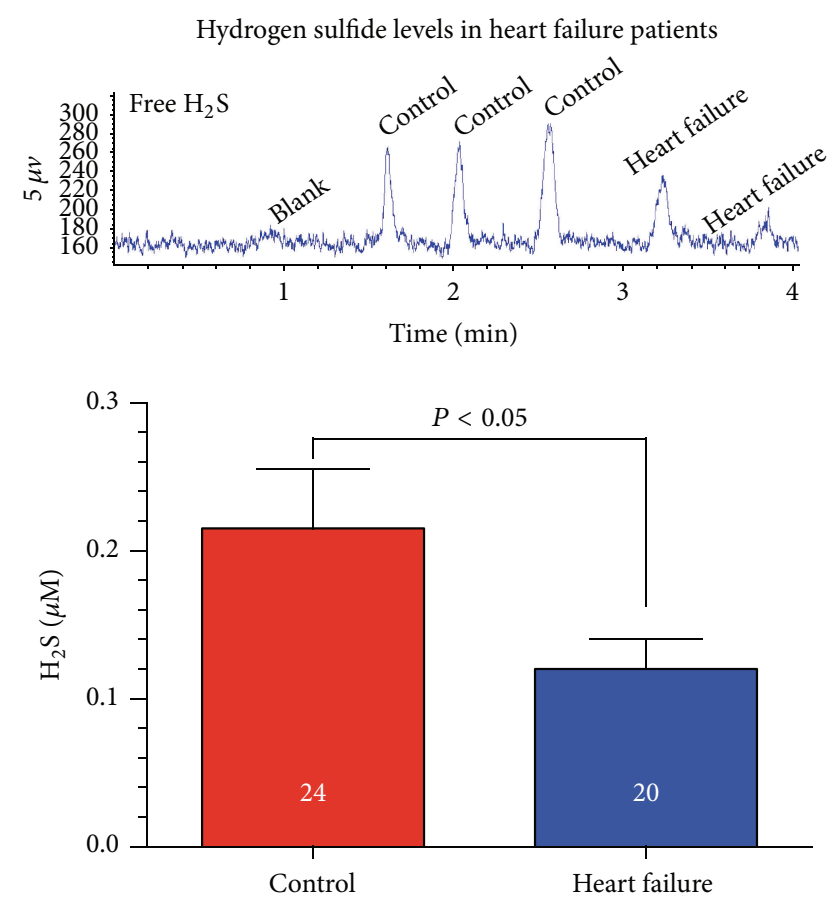

Figure 2: Circulating hydrogen sulfide levels are diminished in heart failure patients. We evaluated $\mathrm{H}_{2} \mathrm{~S}$ levels in heart failure patients $(n=24)$ compared to age-matched control subjects $(n=20)$. Serum free $\mathrm{H}_{2} \mathrm{~S}(\mu \mathrm{M})$ levels were significantly reduced $(P<0.05)$ in heart failure patients. Serum samples were obtained from patients enrolled in the Atlanta Cardiomyopathy Consortium (TACC). This prospective cohort study enrolls patients from the Emory University-affiliated teaching hospitals, the Emory University Hospital and Emory University Hospital Midtown, and Grady Memorial Hospital in Atlanta. All patients undergo detailed medical history surveys, electrocardiogram, standardized questionnaires, and blood and urine sample collection at baseline. All patients provide written informed consent prior to enrollment. The Emory University Institutional Review Board has approved this study. $\mathrm{H}_{2} \mathrm{~S}$ levels were measured in the blood according to previously described methods [20].

circulating $\mathrm{H}_{2} \mathrm{~S}$ levels following TAC compared to naive mice. This finding was in accordance with our discovery that heart failure patients have a $\mathrm{H}_{2} \mathrm{~S}$ deficiency. We next compared mice devoid of the CSE enzyme to wild type mice following TAC. CSE KO mice exhibited significantly greater cardiac dilatation and exacerbated dysfunction than wild-type mice, indicating the demand of $\mathrm{H}_{2} \mathrm{~S}$ to protect against pressure overload heart failure. We then examined $\mathrm{H}_{2} \mathrm{~S}$ therapy in the setting of heart failure. SG-1002, an $\mathrm{H}_{2} \mathrm{~S}$ donor, was infused in the chow and was continuously administered throughout the study beginning the day of aortic constriction. Interestingly, the therapy prevented cardiac dilatation and preserved LV function throughout the 12-week course of the study. Morphological analysis after TAC revealed that $\mathrm{H}_{2} \mathrm{~S}$ treated mice had minor cardiac enlargement compared to the vehicle group, indicating reduced hypertrophy. Similar analysis displayed less pulmonary edema in the $\mathrm{H}_{2} \mathrm{~S}$ treated group. 


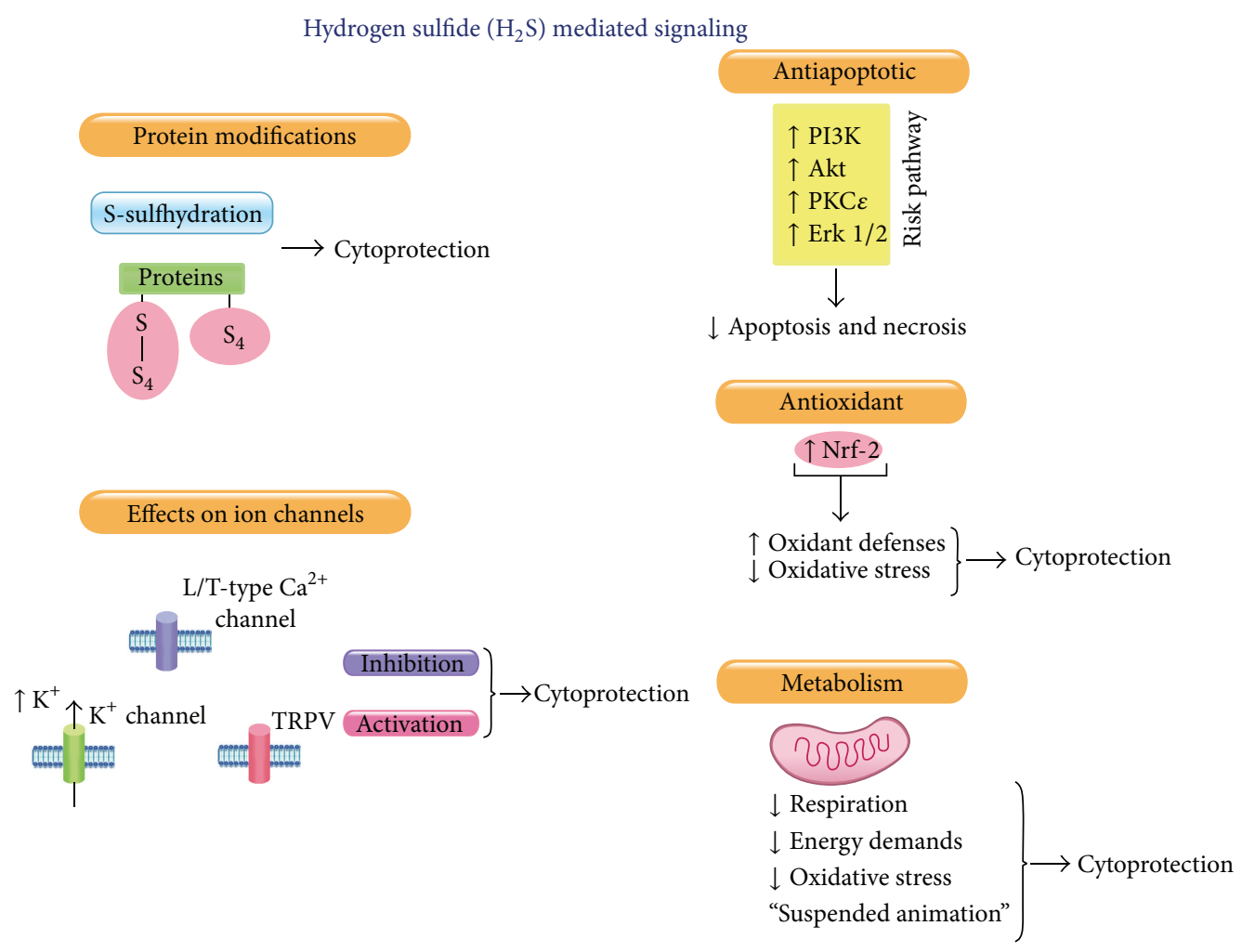

FIGURE 3: Hydrogen sulfide cardioprotective signaling. $\mathrm{H}_{2} \mathrm{~S}$ is known to modify proteins (s-sulfhydration), to modify the function of various ion channels (i.e., $\mathrm{Ca}^{2+}, \mathrm{K}^{+}$, and TRPV), to mitigate apoptosis and oxidative stress, and to be a potent modulator of cellular metabolism.

In addition to its antioxidant actions and mitochondrial protection, $\mathrm{H}_{2} \mathrm{~S}$ appears to promote angiogenic responses and inhibit fibrosis during heart failure. Histological analysis revealed that left ventricular intermuscular and perivascular fibrosis were significantly attenuated at 6 weeks following TAC in the $\mathrm{H}_{2} \mathrm{~S}$ treated group [41]. Mice treated with $\mathrm{H}_{2} \mathrm{~S}$ donors in the setting of heart failure also displayed significantly greater VEGF (a potent angiogenic cytokine) and $\mathrm{CD}_{31}{ }^{+}$(an endothelial cell marker) expression in the myocardium.

Other studies have concurred that the downregulation of $\mathrm{H}_{2} \mathrm{~S}$ is involved in the pathogenesis of cardiomyopathy induced by Adriamycin [42] and myocardial injury induced by isoproterenol [43]. In these studies, myocardial injury resulted in decreased CSE activity, reduced heart and plasma $\mathrm{H}_{2} \mathrm{~S}$ levels, and increased oxidative stress. However, total CSE gene expression was elevated in the heart failure models. These findings were in accordance with our pressure overload induced heart failure model where we observed a robust CSE protein expression but a significant decrease in blood and myocardial $\mathrm{H}_{2} \mathrm{~S}$ levels compared to sham mice [20].

\section{Mechanisms of Cardioprotection}

Many of the cardioprotective mechanisms resulting from $\mathrm{H}_{2} \mathrm{~S}$ therapy in acute $\mathrm{MI}$ and congestive heart failure are similar (Figure 3). For example, $\mathrm{H}_{2} \mathrm{~S}$ promotes the translocation of the nuclear transcription factor, Nrf2, from the cytosol to the nucleus resulting in the subsequent expression of numerous detoxifying genes such as heme oxygenase 1 (HO-1), superoxide dismutase, and catalase $[44,45]$. In addition, $\mathrm{H}_{2} \mathrm{~S}$ protects cells against oxidative stress by increasing glutathione levels in a cysteine dependent manner [46]. Although $\mathrm{H}_{2} \mathrm{~S}$ acts independently to activate antioxidant and prosurvival signals, crosstalk between $\mathrm{H}_{2} \mathrm{~S}$ and $\mathrm{NO}$ may also play an important role [21, 47]. $\mathrm{H}_{2} \mathrm{~S}$ is known to activate endothelial nitric oxide synthase (eNOS) and augment $\mathrm{NO}$ bioavailability $[20,41]$. NO is well established as a signaling molecule with antioxidant characteristics $[48,49]$ and may enhance these protective signaling actions.

$\mathrm{H}_{2} \mathrm{~S}$ also plays a critical role in the protection of mitochondria during ischemic states in a manner that significantly attenuates cell death and apoptosis [26, 50]. Following MI/R injury, $\mathrm{H}_{2} \mathrm{~S}$ treated mice exhibited diminished activation of caspase- 3 and a decreased TUNEL positive nuclei count [25]. $\mathrm{H}_{2} \mathrm{~S}$ also promotes antiapoptotic signaling pathways by altering p38, Erk 1/2, and PI3K expression [51, 52]. Acutely, $\mathrm{H}_{2} \mathrm{~S}$ attenuates mitochondrial respiration to induce a "suspendedanimation-" like state and reduces cellular respiration and oxygen demand $[29,53]$. Establishing this state can preserve mitochondrial function by reducing oxidative stress and mitigating apoptotic signaling. This renders $\mathrm{H}_{2} \mathrm{~S}$ particularly protective against myocyte injury in settings such as acute $\mathrm{MI} / \mathrm{R}$.

One of the earliest proposed benefits of $\mathrm{H}_{2} \mathrm{~S}$ as a physiological modulator on the vasculature is its ability to 
prevent inflammation $[6,7,54] . \mathrm{H}_{2} \mathrm{~S}$ prevents leukocyte adhesion to the vessel wall and inhibits the expression of adhesion molecules [55]. Moreover, in naïve animals, $\mathrm{H}_{2} \mathrm{~S}$ has promoted vessel growth and suppressed antiangiogenic factors $[56,57] . \mathrm{H}_{2} \mathrm{~S}$ has also been shown to decelerate the progression of cardiac remodeling and promote angiogenesis in a congestive heart failure $[20,41]$. Angiogenesis is a complex biological process that involves extracellular matrix remodeling and endothelial growth, migration, and assembly into capillary structures [58]. Decompensated heart failure is associated with a decline in vascular growth and reduced blood flow [57], so $\mathrm{H}_{2} \mathrm{~S}$ may be an attractive therapeutic option for the treatment of the progression of heart failure.

\section{Future Directions}

A number of laboratories have clearly demonstrated the cardioprotective actions of $\mathrm{H}_{2} \mathrm{~S}$ in both acute myocardial infarction and heart failure [59-62]. The mechanisms responsible for these protective effects include the downregulation of oxidative stress responses, modulation of mitochondrial respiration, attenuation of apoptosis, and increasing vascular growth and angiogenesis. $\mathrm{H}_{2} \mathrm{~S}$ is known to activate multiple and diverse pathways simultaneously and exhibits crosstalk with the $\mathrm{NO}$ and $\mathrm{CO}$ signal pathways to amplify a cytoprotection response. In addition, $\mathrm{H}_{2} \mathrm{~S}$ freely circulates throughout the body, diffuses across cellular membranes, and acts on multiple cellular targets [63]. Furthermore, the actions of $\mathrm{H}_{2} \mathrm{~S}$ are not limited to the heart muscle alone but can impact the entire cardiovascular system including blood vessels [7]. In fact, with this field only recently developing, there are tremendous opportunities for further discovery relating to $\mathrm{H}_{2} \mathrm{~S}$ physiology, pharmacology, and pathology. Recent experimental data provide evidence that $\mathrm{H}_{2} \mathrm{~S}$ can prevent atherosclerosis and promotes angiogenesis in the peripheral arteries $[55,64]$. This may prove beneficial when treating vascular diseases that demand collateral vessel growth such as peripheral artery disease (PAD) and critical limb ischemia (CLI). Recently, several groups have reported that $\mathrm{H}_{2} \mathrm{~S}$ also plays a role in pulmonary hypertension and acute lung injury $[65,66]$. Although $\mathrm{H}_{2} \mathrm{~S}$ does not have the potent vasodilation capabilities of $\mathrm{NO}$, the combination of vascular smooth muscle relaxation and potent antioxidant properties may be the source for protection against pulmonary hypoxia and hypertension. In both the liver and the kidneys, $\mathrm{H}_{2} \mathrm{~S}$ is a protective preconditioning agent against ischemia/reperfusion injury $[67,68]$. Similarly to myocardial ischemia/reperfusion protection, $\mathrm{H}_{2} \mathrm{~S}$ protects by its ability to mitigate apoptosis and modulate oxidative stress.

Discovering the most effective $\mathrm{H}_{2} \mathrm{~S}$ donors is also a challenge facing the field. Drugs such as $\mathrm{NaHS}, \mathrm{Na}_{2} \mathrm{~S}$, and GYY4137 are all effective $\mathrm{H}_{2} \mathrm{~S}$ donors, but their rapid halflife renders them less effective for treating chronic diseases. The slow releasing polysulfides deliver a more gradual release of $\mathrm{H}_{2} \mathrm{~S}$ [32]. Other proposed sulfide-modulating agents such as S-propargyl-cysteine do not substantially raise $\mathrm{H}_{2} \mathrm{~S}$ levels in vivo [69]. Dietary formulations, such as SG-1002, can be used as medical foods to replenish an $\mathrm{H}_{2} \mathrm{~S}$ deficiency that may occur from diseases such as heart failure. Because of the short half-life of $\mathrm{H}_{2} \mathrm{~S}$ (estimated to be between seconds and minutes $[17,70]$ ), developing a drug with specific on-site (organ or organelle specific) delivery would also be beneficial.

Following in the footsteps of nitric oxide and carbon monoxide, hydrogen sulfide is rapidly emerging as a critical cardiovascular signaling molecule. Although the complete actions of this gas remain under investigation, the therapeutic options relating to cardiovascular disease are extremely promising. The coming years or research will dictate the means of utilizing this molecule effectively against various cardiovascular disease states.

\section{Conflict of Interests}

David J. Lefer is a founder of the company Sulfagenix and has significant stock in Sulfagenix. David J. Lefer is also the Chief Scientific Officer for Sulfagenix. Sulfagenix is currently developing hydrogen sulfide $\left(\mathrm{H}_{2} \mathrm{~S}\right)$ based therapeutics for the treatment of cardiovascular and other diseases. There are no other conflicts.

\section{Acknowledgments}

The authors would like to thank The Atlanta Cardiomyopathy Consortium (TACC) for generously providing blood samples from heart failure patients for the measurement of hydrogen sulfide. This work was supported by Grants from the National Heart, Lung, and Blood Institute (National Institutes of Health; 1R01 HL092141, 1R01 HL093579, 1U24 HL 094373, and 1P20 HL113452 to David J. Lefer). The authors are also grateful for the generous funding support from TEVA USA Scholars Program and the LSU Medical School Alumni Association.

\section{References}

[1] B. Ramazzini, "De morbis artificum diatriba [diseases of workers]. 1713," The American Journal of Public Health, vol. 91, no. 9, pp. 1380-1382, 2001.

[2] K. Abe and H. Kimura, "The possible role of hydrogen sulfide as an endogenous neuromodulator," The Journal of Neuroscience, vol. 16, no. 3, pp. 1066-1071, 1996.

[3] R. Wang, "Physiological implications of hydrogen sulfide: a whiff exploration that blossomed," Physiological Reviews, vol. 92, no. 2, pp. 791-896, 2012.

[4] M. V. Chan and J. L. Wallace, "Hydrogen sulfide-based therapeutics and gastrointestinal diseases: translating physiology to treatments," The American Journal of PhysiologyGastrointestinal and Liver Physiology, vol. 305, no. 7, pp. G467G473, 2013.

[5] S. Fiorucci, E. Antonelli, E. Distrutti et al., "Inhibition of hydrogen sulfide generation contributes to gastric injury caused by anti-inflammatory nonsteroidal drugs," Gastroenterology, vol. 129, no. 4, pp. 1210-1224, 2005.

[6] S. Fiorucci, E. Distrutti, G. Cirino, and J. L. Wallace, "The emerging roles of hydrogen sulfide in the gastrointestinal tract and liver," Gastroenterology, vol. 131, no. 1, pp. 259-271, 2006.

[7] R. C. O. Zanardo, V. Brancaleone, E. Distrutti, S. Fiorucci, G. Cirino, and J. L. Wallace, "Hydrogen sulfide is an endogenous 
modulator of leukocyte-mediated inflammation," The FASEB Journal, vol. 20, no. 12, pp. 2118-2120, 2006.

[8] D. E. Barañano and S. H. Snyder, "Neural roles for heme oxygenase: contrasts to nitric oxide synthase," Proceedings of the National Academy of Sciences of the United States of America, vol. 98, no. 20, pp. 10996-11002, 2001.

[9] J. W. Elrod, M. R. Duranski, W. Langston et al., "eNOS gene therapy exacerbates hepatic ischemia-reperfusion injury in diabetes: a role for enos uncoupling," Circulation Research, vol. 99, no. 1, pp. 78-85, 2006.

[10] W. A. Pryor, K. N. Houk, C. S. Foote et al., "Free radical biology and medicine: it's a gas, man!," The American Journal of Physiology-Regulatory Integrative and Comparative Physiology, vol. 291, no. 3, pp. R491-R511, 2006.

[11] R. Bolli, "Cardioprotective function of inducible nitric oxide synthase and role of nitric oxide in myocardial ischemia and preconditioning: an overview of a decade of research," Journal of Molecular and Cellular Cardiology, vol. 33, no. 11, pp. 18971918, 2001.

[12] V. L. Dawson, T. M. Dawson, D. A. Bartley, G. R. Uhl, and S. H. Snyder, "Mechanisms of nitric oxide-mediated neurotoxicity in primary brain cultures," The Journal of Neuroscience, vol. 13, no. 6, pp. 2651-2661, 1993.

[13] T. M. Dawson and S. H. Snyder, "Gases as biological messengers: nitric oxide and carbon monoxide in the brain," The Journal of Neuroscience, vol. 14, no. 9, pp. 5147-5159, 1994.

[14] J. E. Clark, P. Naughton, S. Shurey et al., "Cardioprotective actions by a water-soluble carbon monoxide-releasing molecule," Circulation Research, vol. 93, pp. e2-e8, 2003.

[15] P. Kamoun, "Endogenous production of hydrogen sulfide in mammals," Amino Acids, vol. 26, no. 3, pp. 243-254, 2004.

[16] D. J. Polhemus and D. J. Lefer, "Emergence of hydrogen sulfide as an endogenous gaseous signaling molecule in cardiovascular disease," Circulation Research, vol. 114, no. 4, pp. 730-737, 2014.

[17] R. Wang, "Two's company, three's a crowd: can $\mathrm{H}_{2} \mathrm{~S}$ be the third endogenous gaseous transmitter?" The FASEB Journal, vol. 16, no. 13, pp. 1792-1798, 2002.

[18] D. Boehning and S. H. Snyder, "Novel neural modulators," Annual Review of Neuroscience, vol. 26, pp. 105-131, 2003.

[19] N. Shibuya, M. Tanaka, M. Yoshida et al., "3-mercaptopyruvate sulfurtransferase produces hydrogen sulfide and bound sulfane sulfur in the brain," Antioxidants and Redox Signaling, vol. 11, no. 4, pp. 703-714, 2009.

[20] K. Kondo, S. Bhushan, A. L. King et al., " $\mathrm{H}_{2} \mathrm{~S}$ protects against pressure overload-induced heart failure via upregulation of endothelial nitric oxide synthase," Circulation, vol. 127, no. 10, pp. 1116-1127, 2013.

[21] A. L. King, D. J. Polhemus, S. Bhushan et al., "Hydrogen sulfide cytoprotective signaling is endothelial nitric oxide synthasenitric oxide dependent," Proceedings of the National Academy of Sciences of the United States of America, vol. 111, no. 8, pp. 31823187, 2014.

[22] C. J. L. Murray and A. D. Lopez, "Mortality by cause for eight regions of the world: Global Burden of Disease Study," The Lancet, vol. 349, no. 9061, pp. 1269-1276, 1997.

[23] S. M. Haffner, S. Lehto, T. Rönnemaa, K. Pyörälä, and M. Laakso, "Mortality from coronary heart disease in subjects with type 2 diabetes and in nondiabetic subjects with and without prior myocardial infarction," The New England Journal of Medicine, vol. 339, no. 4, pp. 229-234, 1998.
[24] N. S. Dhalla, A. B. Elmoselhi, T. Hata, and N. Makino, "Status of myocardial antioxidants in ischemia-reperfusion injury," Cardiovascular Research, vol. 47, no. 3, pp. 446-456, 2000.

[25] J. W. Elrod, J. W. Calvert, J. Morrison et al., "Hydrogen sulfide attenuates myocardial ischemia-reperfusion injury by preservation of mitochondrial function," Proceedings of the National Academy of Sciences of the United States of America, vol. 104, no. 39, pp. 15560-15565, 2007.

[26] E. Murphy and C. Steenbergen, "Preconditioning: the mitochondrial connection," Annual Review of Physiology, vol. 69, pp. 51-67, 2007.

[27] N. Zamzami, P. Marchetti, M. Castedo et al., "Sequential reduction of mitochondrial transmembrane potential and generation of reactive oxygen species in early programmed cell death," Journal of Experimental Medicine, vol. 182, no. 2, pp. 367-377, 1995.

[28] L. B. Becker, "New concepts in reactive oxygen species and cardiovascular reperfusion physiology," Cardiovascular Research, vol. 61, no. 3, pp. 461-470, 2004.

[29] E. Blackstone, M. Morrison, and M. B. Roth, " $\mathrm{H}_{2} \mathrm{~S}$ induces a suspended animation-like state in mice," Science, vol. 308, no. 5721, p. 518, 2005.

[30] Q. Chen, A. K. S. Camara, D. F. Stowe, C. L. Hoppel, and E. J. Lesnefsky, "Modulation of electron transport protects cardiac mitochondria and decreases myocardial injury during ischemia and reperfusion," The American Journal of Physiology-Cell Physiology, vol. 292, no. 1, pp. C137-C147, 2007.

[31] Q. Chen, S. Moghaddas, C. L. Hoppel, and E. J. Lesnefsky, "Reversible blockade of electron transport during ischemia protects mitochondria and decreases myocardial injury following reperfusion," Journal of Pharmacology and Experimental Therapeutics, vol. 319, no. 3, pp. 1405-1412, 2006.

[32] B. L. Predmore, K. Kondo, S. Bhushan et al., "The polysulfide diallyl trisulfide protects the ischemic myocardium by preservation of endogenous hydrogen sulfide and increasing nitric oxide bioavailability," The American Journal of Physiology-Heart and Circulatory Physiology, vol. 302, no. 11, pp. H2410-H2418, 2012.

[33] C. Chen, D. Pung, V. Leong et al., "Induction of detoxifying enzymes by garlic organosulfur compounds through transcription factor Nrf2: effect of chemical structure and stress signals," Free Radical Biology and Medicine, vol. 37, no. 10, pp. 1578-1590, 2004.

[34] T. Fukao, T. Hosono, S. Misawa, T. Seki, and T. Ariga, “The effects of allyl sulfides on the induction of phase II detoxification enzymes and liver injury by carbon tetrachloride," Food and Chemical Toxicology, vol. 42, no. 5, pp. 743-749, 2004.

[35] C. Wu, C. Lii, S. Tsai, and L. Sheen, "Diallyl trisulfide modulates cell viability and the antioxidation and detoxification systems of rat primary hepatocytes," Journal of Nutrition, vol. 134, no. 4, pp. 724-728, 2004.

[36] T. Zeng, C. Zhang, Z. Zhu, L. Yu, X. Zhao, and K. Xie, "Diallyl trisulfide (DATS) effectively attenuated oxidative stressmediated liver injury and hepatic mitochondrial dysfunction in acute ethanol-exposed mice," Toxicology, vol. 252, no. 1-3, pp. 86-91, 2008.

[37] R. S.-Y. Foo, K. Mani, and R. N. Kitsis, "Death begets failure in the heart," The Journal of Clinical Investigation, vol. 115, no. 3, pp. 565-571, 2005.

[38] A. Cohen-Solal, F. Beauvais, and D. Logeart, "Heart failure and diabetes mellitus: epidemiology and management of an alarming association," Journal of Cardiac Failure, vol. 14, no. 7, pp. 615-625, 2008. 
[39] E. A. Peter, X. Shen, S. H. Shah et al., "Plasma free $\mathrm{H}_{2} \mathrm{~S}$ levels are elevated in patients with cardiovascular disease," The American Heart Association, vol. 2, no. 5, Article ID e000387, 2013.

[40] S. Bhushan, K. Kondo, D. J. Polhemus et al., "Nitrite therapy improves left ventricular function during heart failure via restoration of nitric oxide-mediated cytoprotective signaling," Circulation Research, vol. 114, no. 8, pp. 1281-1291, 2014.

[41] D. J. Polhemus, K. Kondo, S. Bhushan et al., "Hydrogen sulfide attenuates cardiac dysfunction after heart failure via induction of angiogenesis," Circulation: Heart Failure, vol. 6, no. 5, pp. 1077-1086, 2013.

[42] Y. Su, C. Liang, H. Jin et al., "Hydrogen sulfide regulates cardiac function and structure in adriamycin-induced cardiomyopathy," Circulation Journal, vol. 73, no. 4, pp. 741-749, 2009.

[43] B. Geng, L. Chang, C. Pan et al., "Endogenous hydrogen sulfide regulation of myocardial injury induced by isoproterenol," Biochemical and Biophysical Research Communications, vol. 318, no. 3, pp. 756-763, 2004.

[44] H. Motohashi and M. Yamamoto, "Nrf2-Keap1 defines a physiologically important stress response mechanism," Trends in Molecular Medicine, vol. 10, no. 11, pp. 549-557, 2004.

[45] K. Chan, X. Han, and Y. W. Kan, "An important function of Nrf2 in combating oxidative stress: detoxification of acetaminophen," Proceedings of the National Academy of Sciences of the United States of America, vol. 98, no. 8, pp. 4611-4616, 2001.

[46] Y. Kimura and H. Kimura, "Hydrogen sulfide protects neurons from oxidative stress," The FASEB Journal, vol. 18, no. 10, pp. 1165-1167, 2004.

[47] R. Hosoki, N. Matsuki, and H. Kimura, "The possible role of hydrogen sulfide as an endogenous smooth muscle relaxant in synergy with nitric oxide," Biochemical and Biophysical Research Communications, vol. 237, no. 3, pp. 527-531, 1997.

[48] J. Kanner, S. Harel, and R. Granit, "Nitric oxide as an antioxidant," Archives of Biochemistry and Biophysics, vol. 289, no. 1, pp. 130-136, 1991.

[49] L. A. del Río, F. J. Corpas, L. M. Sandalio, J. M. Palma, M. Gómez, and J. B. Barroso, "Reactive oxygen species, antioxidant systems and nitric oxide in peroxisomes," Journal of Experimental Botany, vol. 53, no. 372, pp. 1255-1272, 2002.

[50] C. K. Nicholson and J. W. Calvert, "Hydrogen sulfide and ischemia-reperfusion injury," Pharmacological Research, vol. 62, no. 4, pp. 289-297, 2010.

[51] W. Cai, M. Wang, P. K. Moore, H. Jin, T. Yao, and Y. Zhu, “The novel proangiogenic effect of hydrogen sulfide is dependent on Akt phosphorylation," Cardiovascular Research, vol. 76, no. 1, pp. 29-40, 2007.

[52] Y. Hu, X. Chen, T. Pan et al., "Cardioprotection induced by hydrogen sulfide preconditioning involves activation of ERK and PI3K/Akt pathways," Pflugers Archiv European Journal of Physiology, vol. 455, no. 4, pp. 607-616, 2008.

[53] E. Blackstone and M. B. Roth, "Suspended animation-like state protects mice from lethal hypoxia," Shock, vol. 27, no. 4, pp. 370372, 2007.

[54] M. M. Gadalla and S. H. Snyder, "Hydrogen sulfide as a gasotransmitter," Journal of Neurochemistry, vol. 113, no. 1, pp. 14-26, 2010.

[55] Y. Wang, X. Zhao, H. Jin et al., "Role of hydrogen sulfide in the development of atherosclerotic lesions in apolipoprotein e knockout mice," Arteriosclerosis, Thrombosis, and Vascular Biology, vol. 29, no. 2, pp. 173-179, 2009.
[56] C. Coletta, A. Papapetropoulos, K. Erdelyi et al., "Hydrogen sulfide and nitric oxide are mutually dependent in the regulation of angiogenesis and endothelium-dependent vasorelaxation," Proceedings of the National Academy of Sciences of the United States of America, vol. 109, no. 23, pp. 9161-9166, 2012.

[57] Y. Izumiya, I. Shiojima, K. Sato, D. B. Sawyer, W. S. Colucci, and K. Walsh, "Vascular endothelial growth factor blockade promotes the transition from compensatory cardiac hypertrophy to failure in response to pressure overload," Hypertension, vol. 47, no. 5, pp. 887-893, 2006.

[58] P. Carmeliet, "Angiogenesis in health and disease," Nature Medicine, vol. 9, no. 6, pp. 653-660, 2003.

[59] J. W. Calvert, M. Elston, C. K. Nicholson et al., "Genetic and pharmacologic hydrogen sulfide therapy attenuates ischemiainduced heart failure in mice," Circulation, vol. 122, no. 1, pp. 11-19, 2010.

[60] A. Sivarajah, M. C. McDonald, and C. Thiemermann, "The production of hydrogen sulfide limits myocardial ischemia and reperfusion injury and contributes to the cardioprotective effects of preconditioning with endotoxin, but not ischemia in the rat," Shock, vol. 26, no. 2, pp. 154-161, 2006.

[61] D. Johansen, K. Ytrehus, and G. F. Baxter, "Exogenous hydrogen sulfide $\left(\mathrm{H}_{2} \mathrm{~S}\right)$ protects against regional myocardial ischemiareperfusion injury. Evidence for a role of KATP channels," Basic Research in Cardiology, vol. 101, no. 1, pp. 53-60, 2006.

[62] X. Wang, Q. Wang, W. Guo, and Y. Z. Zhu, "Hydrogen sulfide attenuates cardiac dysfunction in a rat model of heart failure: a mechanism through cardiac mitochondrial protection," Bioscience Reports, vol. 31, no. 2, pp. 87-98, 2011.

[63] R. Wang, "The gasotransmitter role of hydrogen sulfide," Antioxidants and Redox Signaling, vol. 5, no. 4, pp. 493-501, 2003.

[64] M. Wang, W. Cai, N. Li, Y. Ding, Y. Chen, and Y. Zhu, "The hydrogen sulfide donor NaHS promotes angiogenesis in a rat model of hind limb ischemia," Antioxidants and Redox Signaling, vol. 12, no. 9, pp. 1065-1077, 2010.

[65] C. Zhang, J. Du, D. Bu, H. Yan, X. Tang, and C. Tang, “The regulatory effect of hydrogen sulfide on hypoxic pulmonary hypertension in rats," Biochemical and Biophysical Research Communications, vol. 302, no. 4, pp. 810-816, 2003.

[66] A. Esechie, L. Kiss, G. Olah et al., "Protective effect of hydrogen sulfide in a murine model of acute lung injury induced by combined burn and smoke inhalation," Clinical Science, vol. 115, no. 3-4, pp. 91-97, 2008.

[67] S. Jha, J. W. Calvert, M. R. Duranski, A. Ramachandran, and D. J. Lefer, "Hydrogen sulfide attenuates hepatic ischemiareperfusion injury: role of antioxidant and antiapoptotic signaling," The American Journal of Physiology-Heart and Circulatory Physiology, vol. 295, no. 2, pp. H801-H806, 2008.

[68] E. M. Bos, H. G. D. Leuvenink, P. M. Snijder et al., "Hydrogen sulfide-induced hypometabolism prevents renal ischemia/reperfusion injury," Journal of the American Society of Nephrology, vol. 20, no. 9, pp. 1901-1905, 2009.

[69] Q. Gong, Q. Wang, L. Pan, X. Liu, H. Xin, and Y. Zhu, "S-propargyl-cysteine, a novel hydrogen sulfide-modulated agent, attenuates lipopolysaccharide-induced spatial learning and memory impairment: involvement of TNF signaling and NF- $\kappa$ B pathway in rats," Brain, Behavior, and Immunity, vol. 25, no. 1, pp. 110-119, 2011.

[70] M. A. Insko, T. L. Deckwerth, P. Hill, C. F. Toombs, and C. Szabo, "Detection of exhaled hydrogen sulphide gas in rats exposed to 
intravenous sodium sulphide," British Journal of Pharmacology, vol. 157, no. 6, pp. 944-951, 2009.

[71] P. Ward, "Impact from the deep," Scientific American, vol. 295, pp. 64-71, 2006.

[72] J. C. Savage and D. H. Gould, "Determination of sulfides in brain tissue and rumen fluid by ion-interaction reversedphase high-performance liquid chromatography," Journal of Chromatography, vol. 526, pp. 540-545, 1990.

[73] L. R. Goodwin, D. Francom, F. P. Dieken et al., "Determination of sulfide in the brain tissue by gas dialysis/ion chromatography: postmortem studies and two case reports," Journal of Analytical Toxicology, vol. 13, pp. 105-109, 1989.

[74] M. W. Warenycia, J. A. Steele, E. Karpinski, and R. J. Reiffenstein, "Hydrogen sulfide in combination with taurine or cysteic acid reversibly abolishes sodium currents in neuroblastoma cells," Neurotoxicology, vol. 10, pp. 191-200, 1989.

[75] A. K. Mustafa, M. M. Gadalla, N. Sen et al., " $\mathrm{H}_{2} \mathrm{~S}$ signals through protein S-sulfhydration," Science Signaling, vol. 2, article ra72, 2009. 

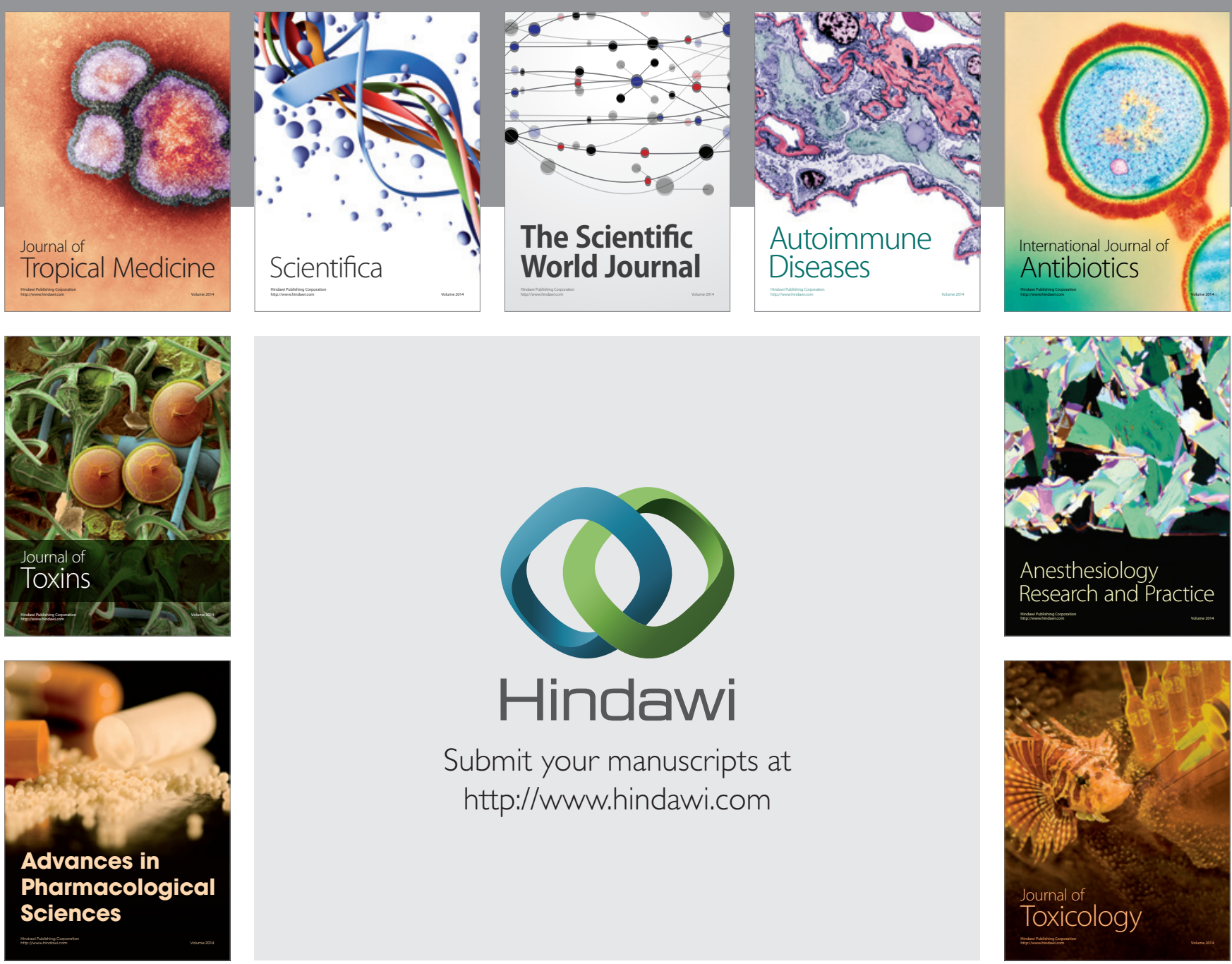

\section{Hindawi}

Submit your manuscripts at

http://www.hindawi.com
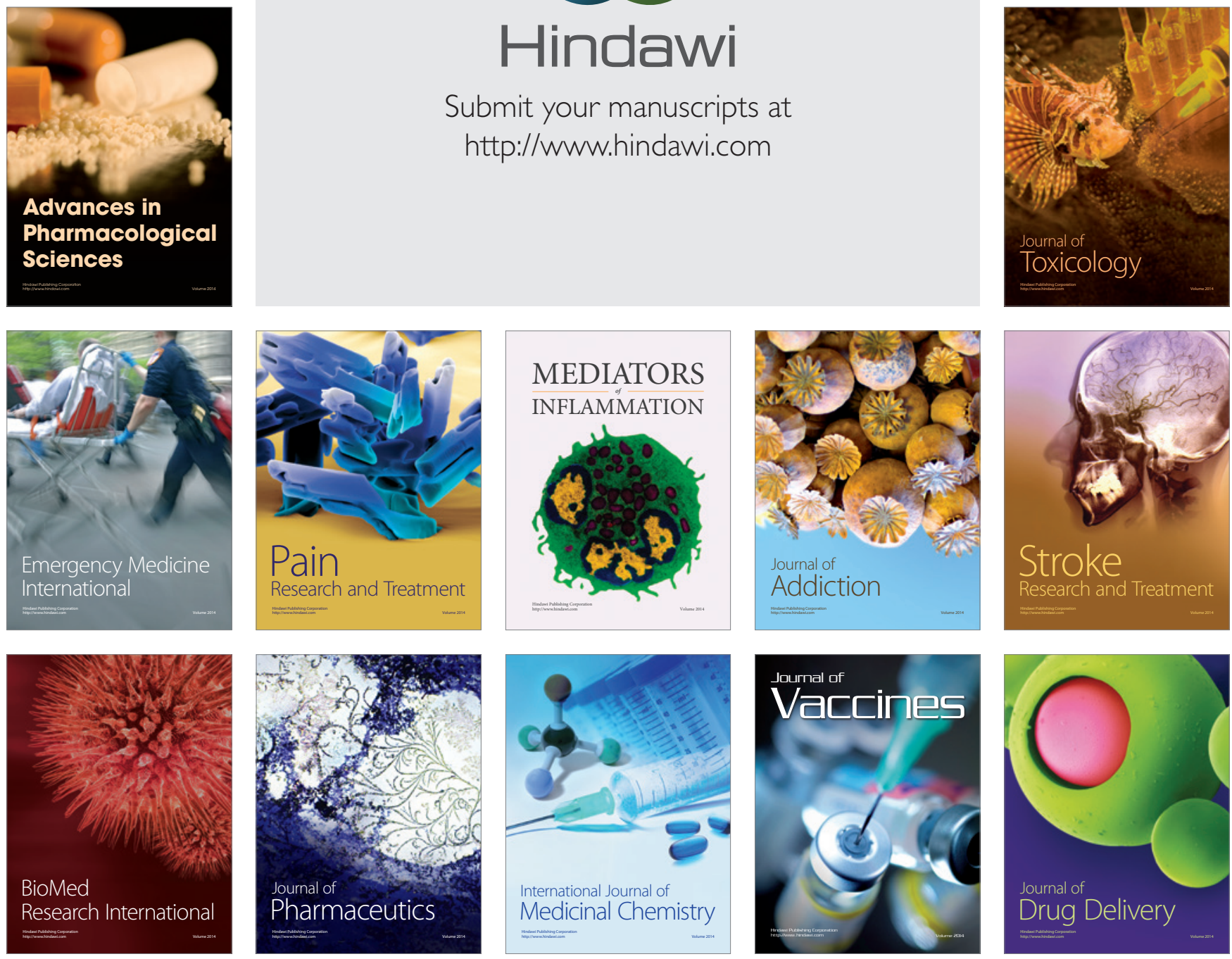